\title{
RECONCILIATION IN IMPLICATURES: DIVERGENCE OF LANGUAGE USE IN DIALOGUES
}

\author{
LOUREMBAM SURJIT SINGH
}

Centre for Advanced Studies in Linguistics, Faculty of Arts Extension Building, University of Delhi, Delhi110007, India

Email: Isurjit24@yahoo.com

\section{ABSTRACT}

This paper proposes to investigate the theory of Gricean $(1975,1989)$ Figure of Speech within the framework of conversational implicatures in the dialogues of a very popular Manipuri Radio play. The Gricean figure of speech exploits or flouts the first maxim i.e. known as maxims of quality. In these maxims exploitation, he subsumes metaphor, irony, hyperbole and meiosis into implicatures as particularized implicatures to convey non-literal meaning. At the same time, in the figure of speech, he reconciled the implied meanings through his maxims and sub-maxims.

It reveals divergence of meanings in language use, particularly in the study of dialogues in the play. When he reconciled the maxims of quality in various figures of speech, he flouted the maxims of truthfulness.

Keywords: Gricean implicature; conversational implicatures; reconciliation in implicatures; divergence in language use; dialogues.

\section{Academic Discipline And Sub-Disciplines}

Linguistics

\section{SUBJECT CLASSIFICATION}

Pragmatics

\section{TYPE (METHOD/APPROACH)}

Literary Analysis; Radio Dialogues

\section{Council for Innovative Research}

Peer Review Research Publishing System

Journal: Journal of Advances in Linguistics

Vol 6, No. 2

editor@cirjal.com

www.cirjal.com, www.cirworld.com 


\section{INTRODUCTION}

The Grice's reconciliation in implicatures has divergence of meanings in language use, particularly in the voice dialogues in a very popular Manipuri Radio play of Moirangthem Inao named "Nongallabasu Thaballei Manam" (Lingering Fragrance) that was broadcast from All India Radio, Imphal (AIR, Imphal) on $2^{\text {nd }}$ April, 1995 at 12:00 P.M.. In the dialogues of this play, the features of cooperative principles and its associated sub-maxims (Grice; 1975, 1989) are using in the notion of figure of speech such as metaphor, irony, meiosis and hyperbole. In various dialogues in the play, the style of using language by Inao is an instrumentally contextual interpretation of "what is said" is distinct from "what is merely meant" in a sentence.

According to Grice, "what is meant" is a conversational meaning whereas "What is said" is closely related to the conventional meaning of the sentence uttered. It is limited to what is meant conventionally by the sentence, and does not include whatever else the speaker may have been trying to convey (Logic and Conversation, 1975). This statement clarifies that the conversational implicature depends on the situations and contexts of the conversation and not just on the conventional meanings of the words used. Therefore, it is not necessary that the implied meaning of the intentionality of the speaker implicatures and conventionality of the sentence implicatures are related. In his theory, the additional meaning is inferred and predicted by the listener self to co-operate in the conversation. In this way, Grice rationalizes implicatures to posit Cooperative and General Principles. In the rationalization of cooperative principles, the maxims help cooperative principle to describe how effective communication has done in various conversational situations. For this purpose, he categorised the maxims into four sub-maxims such as the Maxims of Quality, Quantity, Relevant and Manner.

In the statements of these maxims, maxim of quality states that "Try to make your contribution one that is true". Two more sub-statements made in the maxim of quality i.e. the first maxim (QL1) states "Do not say what you believe to be false", and second maxim (QL2) states "Do not say that for which you lack adequate evidence". For making true information, Grice composes an aspect of this supermaxim in different ways. Each maxim has at least one aspect, under which the characteristics of these maxims differ drastically such as the QL1-maxim that maintains strict guideline for the participants. It instructs participants to exercise only the information that they believe is true. It means that the unknown information cannot exchanged as follows from this maxim, whereas, in QL2-maxim, the participants are required to exercise their judgment as to the adequate evidence of their response.

On the other hand, along with these maxims and sub-maxims Grice nicely subsumes "Figure of Speech" such as metaphor, irony, hyperbole and meiosis into implicature as particularized implicature to convey non-literal meaning. Here, we use Figure of Speech contextually in particular situation of "What is said" to mean something else in the utterances.

We organize our work as in the following. In section 1.1, the theory and method that we used to analyse figure of speech in the proposed play, is discussed. The detail results and discussions are presented in section 2 entitled "Use of Figurative Speech in the Play. Some conclusions are drawn based on the results that we analysed.

\section{THEORY AND METHODS}

The study of the use of dialogues in a play as figurative speech is a challenging task which involves various background of analysis. However, to explore the internal interpretations of nonliteral meaning of the dialogues of a play the Grice's (1975) particularized implicature specifically figure of speech such as metaphor, irony, hyperbole and meiosis is investigated descriptively in the dialogues as a framework in this study.

Grice's concept of 'figure of speech' or 'figurative speech' is a topic which has recently argued by various scholars, particularly, against the explanation of figure of speech as particularized implicature. But, until yet this argument is not conclusive in the study of advanced pragmatics. Camp (2006) says that this has left a space for defending the conception of figurative language like metaphor as implicature. Supporting to Camp's contextualization of metaphor and what is said, I strongly claim here to reintroduce the concept of figurative speech within the background of Gricean statement in the first case of this study. "Figurative Speech is a word which is a fascinate nonliteral in the meaning. Figurative words can be a special repetition, arrangement or omission with the literal meanings because the function and meaning of these words is implied in a particular context and it creates own spaces in the interpretation of meanings. So, the meaning of a figurative word is interesting, effective, attractive, convincing and constructive to the recipients or hearers or readers". In figurative words, the meaning which is interpreted from a word is always different from what is uttered in the sentence, though they are captured by the/a literal paraphrase. It is happened due to the use of all the figurative words all the figurative words are used with the aims of invention in the language use to accentuate the effect of what is being said in the context. For instance, in the sentence like "I had butterflies in my stomach" metaphorically referring to somebody's physical sensation of nervousness feeling as if there was flying insects in the stomach. But from the actual utterance of literal or words meaning it means an insect is inside the stomach.

Besides, referring to non-linguistics theories of figurative speech like classical rhetoricians Corbett (1990), Conley (1991), Becker and Pike (1970) and Roberts (1359), they fundamentally operate into four major categories i.e. adiectio (also known as repletion/expansion/superabundance), detracto (also known as subtraction/abridgement/lack), transmutato (also known as transferring) and immutato (also known as switching/interchange/substitution/transmutation). Through these four major categories they operated every figurative word fundamentally and even still serve to encompass the various figure of speech. However, according to Gricean theory of particularized figurative speech, the notion of meaning is contextually non-literal in interpretation as uttering some words which do not always mean what the utterance said. Hence, in the scope of pragmatics the possible descriptive structures of the language use of figurative speech in the play is investigated below with reference to the mentioned framework. 


\section{USE OF FIGURATIVE SPEECH IN THE PLAY}

The CP and the maxims associated with this help us to understand the nuances of meaning in the

dialogues of the play. They also help us to appreciate more insightfully such figure of speech as metaphor, meiosis, irony and hyperbole.

Earlier, metaphor was used only in the application of literature and poetic interpretation. In a literary sense it is used to define as a rhetorical device that transfers the sense or aspects of one word to another. However, after we know its large numbers of metaphoric expression and lexicalized properties the scope of metaphor has been extended metaphorical in the study of linguistics. Metaphor is the term which can be used to express a wide variety of contents and also studied in context-sensitive linguistic phenomenon. In a standard way, metaphor can be treated as a form of speaker meaning on which speakers intentionally say one thing in order to understand something else other than the literal meaning of the utterance (Grice, 1975; Searle, 1979).

Grice's metaphoric interpretation involves in what is said and what is implied (non-literal). He nicely subsumes metaphor into conversational implicature, as particularize implicature, within the context of communication theory. Grice says "You are the cream in my coffee" characteristically involves categorical falsity, so the contradictory of what the speaker has said, will, strictly speaking, be a truism; so it cannot be that that such a speaker is trying to get across. The supposition he made is that speaker is attributing to his audience some feature or features in respect of which the audience resembles more or less fancifully the mentioned substance.

The model of Gricean metaphor is both intuitively plausible and theoretically satisfying. He used metaphor as a means of finding logical meaning in certain communication in order to intend the implied meaning to the listeners. Metaphor results from flouting the first maxim of Quality that of not saying what someone believes to be false. When the maxim of quality is flouted there is a possibility of two stages in interpretation i.e. the interpretant what the speaker metaphorically says as truth into a particular context and then the irony interpretant. He says You are the cream in my coffee, intending the hearer to reach the metaphoric interpretant "You are my pride and joy". Through this contextual meaning, he used to prove that this metaphoric meaning is characteristically involved and then flouted the maxim of truthfulness. However, he did not mention concisely in the regards of categorical falsity. Hence, Gricean metaphor can be accommodated only in contextual and particularize implicature in order to fulfil what is meant in the context, as non-literal meaning of the context. Therefore, most of the implicatures like litotes or understatement, hyperbole or exaggeration, simile, which employ comparison and synecdoche and metonymy, share the same property of being generated by an overt flouting of a conversational maxim. This overt flouting of the maxims in truthfulness is caused due to maxim exploitation. Here, the issue which remains still as unclear in the Gricean metaphor is that manner of recognizing a metaphoric interpretation. However, we may investigate Gricean metaphor $(1975,1989)$ from the following dialogues of the play within the context of particularize implicature:

(Dialogue 96 from the play)

1Phajabi: $\quad n \star \eta n \star t h \star$ wanmicakni man $\star t \star n d \star n, n \star \eta n \star$ numitni...........

(You are the star and he (Tombi) is the glow worm, you are the sun...)

2R.K.: $\mathrm{pumn} \star \mathrm{m} \star \mathrm{ksid} \star \mathrm{n} \star \mathrm{nn} \star \mathrm{k} \star \mathrm{ri}$ ?

(Above all, what about you?)

3Phajabi:

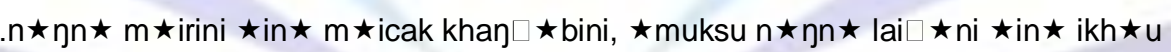

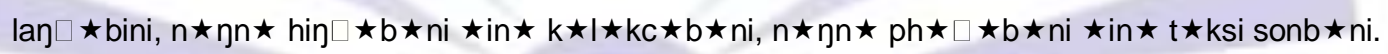

(...... you are the heat and I am the bearer of the heat, you are the water and I am the thirst, you are the beings and I am the admirer, you are the beautiful and I am the envious.)

From the above metaphorical dialogues, the distinction of what Phajabi literally says and what she implicates can be examined as (1) Phajabi literally says that You are the star and he is the glow worm, you are the sun..., this is a proposition that involves a categorical falsity, something she believes to be false. These categorical falsities are caused due to maxim exploitation, where Phajabi intend to mean something else other than what she literally says. The utterance (1) also flouts the first maxim of quality that "Don't say what you believe to be false". Therefore, what Phajabi means is only what Phajabi implicates, and what she implicates depends on the attribution to the star of the features and appearances in respect of which the star resembles more or less the object that can literally glow. Besides, what Phajabi metaphorically implicates with (1) is that he (R.K.) is brighter than him (Tombi) [for her (Phajabi)], the metaphorical meaning is Phajabi loves R.K. more than Tombi. This manner of understanding is that metaphoric situation which is created by the behaviour of CP. Thus, the interpretation of metaphoric utterances proceeds in two propositional stages.

Again in dialogue (3), Phajabi literally says that you are the heat and I am the bearer of the heat, you are the water and $I$ am the thirst, you are the beings and $I$ am the admirer, you are the beautiful and I am the envious, similar to what I mentioned above in (1), this proposition is also involved categorically falsity. But when we are looking to its nonliteral meaning it is characteristically involved and there is a perfect metaphorical interpretation while constructing meaningful utterances. In other aspects, both (1) and (3) compares two things directly in each pair of utterance. These pairs of utterances deserve metaphorical interpretation. 
In addition to Grice, George Lakoff and Mark Johnson (1980) said that the essence of metaphor is to understand and experience one kind of thing in terms of another. It helps to understand the abstract and the identifiable concepts such as "love" or "life in general". A typical metaphor for life is considered as the concept of "journey", "game" or "container". They also argue that metaphors fulfil the necessity of the human mind which facilitate the structuring and understanding of complex or abstract concepts. Therefore, a large property of metaphor belongs to the structural metaphors. For instance, if we used one structural concept for another one is the metaphorical concept i.e. in the dialogue "you are the heat and I am the bearer of the heat". Here, the abstract concept "you" (R.K.) is considered as a source which has similar property with the literal concept "heat" (Phajabi). Hence, the utterances "you are the water and I am the thirst" or "you are the beings and I am the admirer" or "you are the beautiful and I am the envious" etc. have become the acceptable metaphor in Manipuri culture. Thus, metaphor sometimes depends on the particular cultural and societal values.

Besides, Grice (1975) categorized irony as a figure of speech in which the intended meaning is the opposite of that expressed by the words used. It is resulting from an overt violation of the first maxim quality. He remarks "The Irony is perfectly obvious to $A$ and his audience that what $A$ has said or has made as if to say is something he does not believe, and the audience knows that A knows that this is obvious to the audience. So, unless A's utterance is entirely pointless, $A$ must be trying to get across some other proposition than the one he purports to be putting forward. This must be some obviously related proposition; the most obvious related proposition is the contradictory of the one he purports to be putting forward". He says Irony $X$, with whom A has been on close terms until now, has betrayed a personal secret of A's to other rivals. A and his audience both know this, A says $X$ is a faithful friend. In this context, it is clear to both $A$ and his audience that there is incongruity between what is said and what is meant. In this regard, Grice simply says that irony is structurally and contextually opposite to the literal meaning and it covers a wide scope of verbal phenomenon.

Further, in the proposition of metaphor, irony, simile, hyperbole and meiosis, Brown and Levinson (1987) considered that irony is very consistent only in the case of violation of the Maxim of quality. The meaning of irony is always "the opposite" of what is said and it is something there that one is not making a true contribution. Sperber \& Wilson (1981, 1986) also remarked that the treatment of verbal irony parallels the treatments of metaphor and hyperbole. They explained that Grice's irony is an overt violation of the maxim of truthfulness, and differs from hyperbole and metaphor only in the kind of implicature it conveys. The metaphor implicates a simile based on what was said, hyperbole implicates a weakening of what was said, and irony implicates the opposite of what was said. Therefore, similes are metaphor in narrow sense but all the metaphors are not simile. They emphasis irony is the specific utterances in an echoic way. Ironical utterances can be regarded as "making reference to some state of affairs that was predicted, expected or desired, either because of some explicit prediction or based upon a mutually shared domain of knowledge" (Gibbs \& Colston, 2007). Like this, an ironical utterance received understandable interpretation either as explicit echo or implicit echo. The speakers make an ironical remark conveying a certain attitude towards the proposition which they intent to reflect from the literal meaning, opposite to what is said. However, relevance theorists have argued against Gricean analysis and other general assumption of metaphor, irony, hyperbole and meiosis that they cannot be given parallel treatments.

Grice neither had explained the category of ironical interpretation nor characteristically falsity. He just introduced the possibilities of interpretation into two ways as metaphor and irony interpretation. Followings are the ironies which have flouted or violated the maxim of truthfulness in order to intend opposite meaning of what is said.

\section{(Dialogue 5 from the play)}

1R.K.:

$1 \mathrm{ih}$ ! Ih! ibemm $\star$ surtabi surb $\star$ la. 2 ha? $3 \mathrm{n} \star \min p h \star$ ob $\star$ di $n \star m a h o i n \star p h \star \square \star n \star$ thonbir $\star \mathrm{k}-$ i. 4 wa nanb $\mathrm{d} \star$, ha? surse nunsikhr $\star b \star$.

(1Eh! Eh! Rhythmic Surbala, 2 What? 3Your mother has given at least your name very nicely.

4In speaking you are very rhythmic.)

2Surbala: $\quad 1$ moipabunine 'eh..!' haib $\star$ dudine sur tai, nunsi.

(1My Sir's (husband) way of saying "eh...!" is more rhythmic and lovely.)

From the above utterances, in (1) R.K. violates the maxim of truthfulness and tends to use an ironical meaning to Surbala. R.K. says (Gloss: Irony is perfectly obvious to R.K. and Surbala that what R.K. has said or has made as if to say is something he does not believe, Surbala knows that, and R.K. also knows that this is obvious to them) in (1:1 \& 1:4) the way that Surbala says and her voice is not suited in the situation, the rhythm of her voice makes incongruity to him and his intention. R.K. must be trying to get across some other proposition than the one he purports to be putting forward. This must be obviously the most related propositions in the contradictory of the one he purports to be putting forward. As R.K. did in (1) Surbala utters (2) intending opposite meaning to R.K. violating of the maxim of truthfulness.

As for sarcasm, generally irony is used to mean something like "irony with an edge". Mark Liberman (October $\left.22^{\text {nd }}, 2009\right)$ commented on Language Log, irony means: "A sharp, bitter, or cutting expression or remark; a bitter gibe or taunt"- thus irony may or may not be sarcastic, and sarcasm may or may not be ironic". He says sarcasm in this sense is a cultural universal, though the cultural meaning of gibes and taunts can vary quite a bit, from provoking conflict in establishing and maintaining friendship. In other comments of Danny O Brien (October $22^{\text {nd }}, 2009$ ), in case of two different cultures "X culture doesn't understand irony/doesn't use sarcasm" is probably to do with the subtle, and culture-specific, signals that one uses to indicate that one is about to use sarcasm/irony, and the culture-specific list of contexts in which that's it's appropriate to use sarcasm/irony. For instance, Britishers tend to use humour far more in the initial of talk or conversation than other cultures, so that if a speaker doesn't speak humourously they quickly decided that individuals or 
whole cultures are humourless. Such as in Manipuri language, particularly in dialogic language humour and etiquette in speaking is a must in every context. If the speaker doesn't use humour in his speech, it may go to irony or sarcasm in the implied meaning. Manipuri is also used naming words like name of the mountains, rivers and other natural things, as quotation in their speech affixing or mixing the words or lexemes with the utterances intending metaphorical, ironical and sarcastic meaning. It's happened only when someone misunderstood the speaker's intention or s/he belongs to different cultural backgrounds. The following dialogues are used as examples:

(Dialogue 51 \& 52 from the play)

1Phajabi: $\begin{aligned} \text { jambun, jambun........ } b \star s \star n t \star \text { lak-e. } \\ \text { (Brother, Brother........ Spring (Basanta) has come.) }\end{aligned}$

2R.K.: $\quad n \star \eta n \star b \star s \star n t \star$ lak-ebo hi $\square \star m g i r o ?$

(You mean that Hijam Basanta has come?)

3Phajabi: $\quad h \star \ldots . . . m m ! m \star h \star$ usagine, pr $\quad$ kitigi $b \star s \star n t \star$ lak-e haib $\star$ ne.

[(Laughing)...! It's of nature. I do mean that the spring season is started: it has come.]

4R.K.:

Oh! Oh! $\star$ idi hi $\square \star$ mgi b $₫ s \star n t \star l a k p r \star k h \star l l u b \star$.

(Oh..Oh! I was thinking that Hijam Basanta has come.)

From the above dialogues, (1) creates a specific situation which tend to use poetic humour in Manipuri with an aspects of language used. Phajabi says Basanta has come; she intended to say that the spring season is started and it has come. But, (2) says something else opposite to the literal meaning whereas the ambiguous word "Basanta" means a name of his friend called "Basanta". The question that R.K. asks to Phajabi in (2) has made a humourless statement and it is poetically and culturally disobeyed and sarcasm to the initial speaker. Though it is irony in corresponding to (1), it signals overt sarcasm at a much subtle level.

According to Grice, hyperbole violates the first maxim of quality that say what you believe to be true and understatement violating the maxim of quantity that contribute as much to the conversation as is required. In both cases the speakers urge the addressee to seek an implicature beyond the straightforward literal interpretation of what is said. However, hyperbole and understatement violate truthfulness maxims where one assumes that a speaker's utterance must be identical to his or her beliefs. These tropes do not violate or flout truthfulness maxims when one assumes that speakers' utterances need to resemble their beliefs only in the sense of sharing some logical and contextual implications with what the speakers believed (Wilson \& Sperber, 1990). For instance, when Phajabi says (1), she tries to convey some set of implications about the flower which Phajabi similes that as her friend, but in the stated proposition all of these are not required to be identical. Only some implications from her utterances are required with what Phajabi truly believes.

(Dialogue 51 from the play)

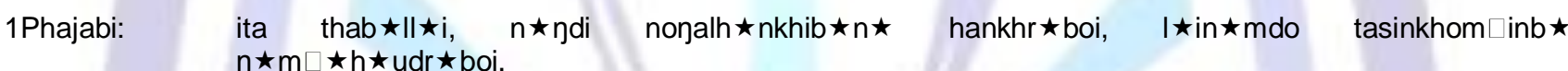
(Dear friend 'Thaaballei' (name of a flower) you let the dawn up before you couldn't recollect the fragrance.)

The term litotes or meiosis is used in which the speaker uses a negative or weak statement to emphasis a positive meaning. Litotes express an overt lack of commitment and so imply a desire to suppress or conceal one's true attitude. Paradoxically litotes or meiosis, like hyperbole, seems to involve intensification, suggesting that the speaker's feelings are too deep for plain expression. In this regards, Grice (1975) exemplified meiosis, by giving an example that "Of a man know to have broken up all the furnitures, one says He was a little intoxicated".

Lastly, Grice treats hyperbole, meiosis or litotes, sarcasm and understatement as the terms of irony that includes figurative language. The presence of metaphor, irony, hyperbole and Meiosis in the way we speak about in our day-to-day life and the way of language used in dialogues of the play provides part of figurative foundation for everyday attitude. These figurative languages and speeches conceptualized incongruous situation of thinking of a speaker, character as well as writer. Therefore, Grice's figurative language is widely applicable in the context of communication theory and also has divergence of language use in voice dialogues. It reveals the meanings of the utterances in different aspects, and also reconciled the theoretical aspects of Gricean implicatures in different societal contexts of Manipur.

\subsection{Conclusions}

The work concludes with how the theories of conversational implicatures have been dealt with in a number of works over many years. Along with this theoretical analysis it attempts to find out a new and innovative method of investigation particularly in the context of dialogues, discovering maximum occurrences and possibilities in Grice's (1975) work.

The study reveals that Grice used Implicatures in conversational pragmatic but the theory of Implicature can also be used figuratively conveying various meanings in diverse contexts. This diversal nature of meanings reconciled figurative speech in Gricean implication theory with many possibilities. The possible of this reconciliation includes the cooperative principles and its sub-maxims based on the notion of using figurative language like figure of speech i.e. irony, 
metaphor, meiosis and hyperbole and grammatical features of the dialogues in the play. However, this work is not in general concerned with the extended experiment of Gricean theory that was amended by Neo-Griceans such as Horn (1989), Chierchia (2004) and Levinson (1983, 1987b, 1995, 2000,) etc. Even though I don't go beyond the limit of Grice's (1975) work for the Manipuri play, I have at some places referred to other scholars.

\section{ACKNOWLEDGEMENTS}

We would like to acknowledge Prof. Rama Kant Agnihotri and Prof. Pradeep Kumar Das for their fruitful comments and suggestions and even for modifying some of the sections in this work.

\section{REFERENCES}

1. Brien, Danny O. (2009). Irony. http://languagelog.Idc.upenn.edu/nll/?p=1835

2. Dan, Sperber and Deirdre, Wilson. (1981). Irony and the Use-mention Distinction, In: P. Cole

3. (ed.), Radical Pragmatics, New York, New York: Academic Press, pp. 295-318.

4. Dan, Sperber and Deirdre, Wilson. (1986). Relevance, Oxford: Blackwell.

5. Dan, Sperber and Deirdre, Wilson. (1986a). Relevance: Communication and Cognition, Cambridge: Harvard University Press.

6. Dan, Sperber and Deirdre, Wilson. (1990). Rhetoric and Relevance, In: David Wellbery and John Bender (eds), The Ends of Rhetoric: History, Theory, Practice, Stanford, Stanford University Press, pp. 140-155.

7. Elisabeth, Camp. (2006). Contextualism, Metaphor, and What is Said, Mind and Language, Hoboken: New Jersey, Wiley-Blackwell, Vol. 21: 3, pp. 280-309.

8. Corbett, E. P. J. (1990). Classical Rhetoric for the Modern Student. New York: Oxford University Press.

9. George, Lakoff \& Johnson, Mark. (1980). Metaphors We Live By. Chicago: University of Chicago Press.

10. Hebert Paul, Grice. (1957). Meaning. The Philosophical Review, Cornell University: Duke University Press, 66, pp. 377-388.

11. Hebert Paul, Grice. (1961). The Causal Theory of Perception, The Aristotelian Society: Proceedings, Supplementary, Vol. 35: pp.121-152.

12. Hebert Paul, Grice. (1967). Logic and Conversation, In (Typescript): William James Lectures, Cambridge, Massachusetts, Harvard University.

13. Hebert Paul, Grice. (1969). Utterer's Meaning and Intentions, The Philosophical Review, Cornell University: Duke University Press, 78, pp. 147-177.

14. Hebert Paul, Grice. (1975a). Logic and Conversation, In: P. Cole and J.L Morgan (eds), Speech Acts, New York: Academic Press, 3, pp. 41-58.

15. Hebert Paul, Grice. (1975b). Logic and Conversation, In: Donald Davidson and Gilbert Harman (Encino, Cal.: Dickenson), (eds), The Logic of Grammar, New York: Academic Press, pp. 64-75.

16. Hebert Paul, Grice. (1978). Further Notes on Logic and Conversation, In: P. Cole (ed), Syntax

17. and Semantics, New York: Academic Press, Vol. 9: pp. 113-127.

18. Hebert Paul, Grice. (1981). Presupposition and Conversational Implicature, In: P. Cole (ed), Radical Pragmatics, New York: Academic Press. pp. 183-197.

19. Hebert Paul, Grice. (1989). Studies in the Way of Word,. Cambridge: Harvard University Press.

20. Hebert Paul, Grice. (1989a). Studies in the Way of Words, Cambridge: Harvard University Press.

21. John, Searle. (1979). Metaphor, In: Andrew Ortony (ed.), Metaphor and Thought, New York: Cambridge University Press.

22. Liberman, Mark. (2009). Irony with an Edge: http://languagelog.ldc.upenn.edu/nll/?m=200910\&paged=2.

23. Moiranthem, Inao. (1995). Naongaalabasu Thaballei Manam (The Lingering Fragrance), Broadcast: $2^{\text {nd }}$ April at 12:00-1:00 PM, All India Radio, Imphal, Manipur: India.

24. Young, R. E, Becker, A. L and Pike, K. L. (1970). Rhetoric: Discovery and Change. New York: Harcourt Brace \& World.

25. Gibbs, R. W. (1999). The Poetics of Mind- Figurative Thought, Language and Understanding, Cambridge: Cambridge University Press, pp.391-394.

26. Gibbs, R.W. and Colston, H.L. (2007). Irony in Language and Thought, New York: Lawrence Erlbaum Associates. 
27. Stephen C, Levinson. (1987). Pragmatics, Cambridge: Cambridge University Press.

28. Thomas, Conley. (1991). Rhetoric in the European Tradition, Chicago: University of Chicago.

29. W. Rhys, Roberts. (1924,1925). Notes on Aristotle's Rhetoric, American Journal of Philology, Johns Hopkins University Press, 45, pp. 351-61.

\section{BIO-NOTE}

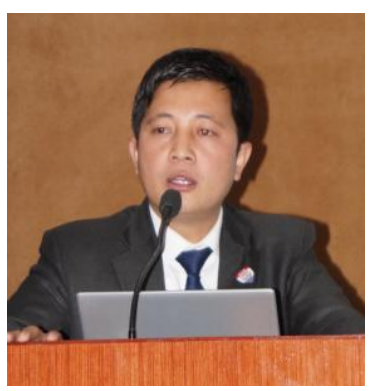

Lourembam Surjit Singh did M.A., M Phil and pursuing PhD in Linguistics from Annamalai University, Tamilnadu, and Centre for Advanced Studies in Linguistics, University of Delhi, Delhi, India respectively. He is also working as an Associate Professor at the Department of Applied Science and Humanities, in IILM-Academy of Higher Learning, Greater Noida, U.P. India. He is the author of a book entitled "Conversational Implicatures in a Voice Play" published by Lambert Academic Publishing, Saarbrücken: Germany, and also has been published many research papers from reputed international journals such as "Morphosemantic Attributes of Meetei Proverbs" published in the Advances in Language and Literary Studies [ALLS], Vol.6, No.3, Australian International Academic Centre PTY. LTD., Footscray: Australia, "Significance of the Correlation in Turn-taking Dialogues" published in the journal The Prague Bulletin of Mathematical linguistics, Mouton De Gruyter, Berlin: German, etc. 